\title{
Social Media and Cyber-Bullying in Autistic Adults
}

\author{
Paraskevi Triantafyllopoulou $^{1}$ (1) - Charlotte Clark-Hughes ${ }^{1} \cdot$ Peter E. Langdon ${ }^{2,3,4}$
}

Accepted: 6 November 2021 / Published online: 19 November 2021

(c) The Author(s) 2021

\begin{abstract}
Social media can lead to rejection, cyber-bullying victimisation, and cyber-aggression, and these experiences are not fully understood as experienced by autistic adults. To investigate this, 78 autistic adults completed self-report measures of social media use, cyber-bullying victimisation, cyber-aggression, and self-esteem. High levels of social media use were found to be associated with an increased risk of cyber-victimisation; whereas self-esteem was positively correlated with feelings of belonging to an online community and negatively correlated with feelings of being ignored on social network sites and chat rooms. Future studies are needed to further investigate the experience of cyber-bullying victimisation of autistic adults.
\end{abstract}

Keywords Autism $\cdot$ Social media $\cdot$ Cyber-bullying victimisation $\cdot$ Cyber-aggression $\cdot$ Internet

\section{Introduction}

Social media has added another dimension to our communication, interaction, and connection with others, and is well integrated into our lives. Social media can broadly be defined as a group of emerging online media which facilitate social interaction; these platforms encompass internet applications such as social networking websites and online forums, as well as virtual gaming (O'Keeffe \& ClarkePearson, 2011). The accessibility, availability, and immediacy of social media (i.e., instant messaging), have made them extremely popular, and the method of choice for the promotion of social engagement (Mazurek \& Engelhardt, 2013). Statista (Tankovska, 2021) reported $93 \%$ of adults in the UK to have had their own social network profile in 2019. It has been suggested that social media use among

Paraskevi Triantafyllopoulou p.triantafyllopoulou@kent.ac.uk

1 Tizard Centre, University of Kent, Cornwallis North East, Canterbury CT2 7NF, Kent, England

2 Centre for Educational Development, Appraisal, and Research (CEDAR) and Centre for Mental Health and Wellbeing Research, University of Warwick, Coventry CV4 7AL, England

3 Rainbow Unit, Coventry and Warwickshire Partnership NHS Trust, Birmingham B37 5RY, England

4 Herefordshire and Worcestershire Health and Care NHS Trust, Worcester WR5 1JR, England young adults often provide enhanced social engagement and functioning (Gross et al., 2002). Online communication has also been suggested to help maintain and strengthen relationships (Reich et al., 2012) resulting in closer friendships and increased friendship quality in adolescents (Blais et al., 2008).

We are stating the obvious by saying that some autistic people use social media for entertainment and to socially connect with others and communicate (Mazurek, 2013). Nevertheless, autism is construed as a lifelong neurodevelopmental condition characterised by deficits in social interaction and communication alongside restricted, repetitive, or stereotyped patterns of behaviours, interests, and activities (American Psychiatric Association, 2013) affecting about $1 \%$ of the population (Russell et al., 2015). Face-to-face interactions are sometimes challenging for autistic individuals due to problems with recognising and processing facial expressions (Rump et al., 2009; Smith et al., 2010). Therefore, social media have been reported as one particularly attractive alternative avenue of communication to help establish social relationships, enhance friendships and reduce the feelings of loneliness in autistic individuals (Blume et al., 2001; Mazurek et al., 2012; Kraut et al., 2002; Shaw \& Gant, 2002; Valkenburg \& Peter, 2007).

Despite its positive aspects, social media use also comes with certain risks, which may be greater for those who have difficulties understanding and responding to social cues (Kowalski \& Fedina, 2011). It has been argued that social media use may lead to victimisation rather than positive 
social interaction (DiMaggio et al., 2001). Other risks include social rejection, cyber-bullying, depression, and other negative consequences related to general well-being (O' Keefee \& Clarke-Pearson, 2011; Valkenburg \& Peter, 2007). The use of technology to advertently harm, annoy or defame others is called 'cyber-bullying' (Kowalski \& Limber, 2013). Cyberbullying is often defined as a form of intentional aggressive behaviour which is then repeated over a period of time. This is done in a deliberate manner to cause significant discomfort or harm (Agatston et al., 2007) and is carried out through the use of electronic means such as: e-mail, social media, images, digital messages, online gaming etc. (Kowalski et al., 2014; Olweus, 1993).

The prevalence of cyber-bullying victimisation is estimated between 37 and $70 \%$ for the general population (Microsoft, 2012; Cramer, 2018). Past research has indicated that individuals with specific types of disabilities are more likely to be victimised in comparison to others, with specific characteristics of their disability enhancing their vulnerability and risk of being targeted (Twyman et al., 2010). Cyber-bullying victimization has been reported for autistic adolescents in China (15\%; Hu et al., 2019), Spain (64.4\%; Iglesias et al., 2019) and Canada (30.4\%; Holfeld et al., 2019), with the differences in prevalence explained possibly by sample differences between the studies. Low levels of cyber-aggression enacted by autistic adolescents has been reported (Hu et al., 2019; Iglesias et al., 2019; Holfeld et al., 2019) with other studies reporting low involvement of autistic adults in cybercrime (Ledingham \& Mills, 2015; Payne et al., 2019).

Authors of previous studies have linked bullying with adverse psychological effects such as depression, low selfesteem (Didden et al., 2009; Kowalski \& Limber, 2013) and anxiety (Holfeld et al., 2019), with cyber-bullying being associated with behavioural, mental health (Holfeld \& Mishna, 2019; Kowalski et al., 2014), and self-esteem (Cenat et al., 2014; Perren et al., 2010) problems. Depression is associated with cybervictimization in adolescents with intellectual and developmental disabilities (Wright, 2017) and excessive social media use is associated with low self-esteem (Kalpidou et al., 2011; Mehdizadeh, 2010), even though some studies have reported the exact opposite in typically developed adolescents (Valkenburg et al., 2005).

\section{Current Study}

Considering the lack of previous research studies on the topic, we completed an online survey to further understand the nature of social media use, cyber-bullying victimisation and cyberaggression amongst autistic adults and whether this is related to their wellbeing. The specific aims of this study were: (i) to investigate social media use in autistic adults, (ii) to examine the occurrence of cyber-bullying victimisation and cyber-aggression in this population, (iii) to examine the relationship between self-esteem and social media use, including time spent online, and cyber-bullying victimization and cyber-aggression.

\section{Method}

\section{Participants}

Data collection took place in 2017 and 2018. In total, 81 individuals opened the online link to the survey, and 78 autistic adults completed at least $70 \%$ of the questionnaires. Twenty-nine participants were male (37.2\%), 43 were female $(55.1 \%)$ and 6 preferred not to state their gender (7.7\%). Participant ages ranged from 18 to 59 years $(M=29.3$, $\mathrm{SD}=9.7)$ and most were white European $(79.2 \%)$. All participants confirmed that they had a diagnosis of autism, and all reported to have access to a personal computer, a laptop, or a smartphone. Just under one half (48.7\%) were currently in education, $16.7 \%$ had a postgraduate degree in higher education, $29.5 \%$ had an undergraduate degree, and $38.5 \%$ had A level (or equivalent) qualifications. The cognitive ability and autism severity of participants was not assessed.

\section{Procedure}

The study was advertised online in relevant autism specific sites and forums. Participation was voluntary and all participants had to provide informed consent prior to completing the questionnaires which were presented using Qualtrics. A hyperlink was made available in the study advertisement that directed potential participants to an online information sheet and consent form. Participants were required to accept participation and give their consent before accessing the online questionnaires. Their identity could be kept anonymous if they did not wish to provide their name. The questionnaires took approximately $15 \mathrm{~min}$ to complete. Ethical approval was gained from the University of Kent prior to the start of the study. Additional information regarding the participants' age, gender, ethnic background, educational background, diagnosis, as well as access to electronic devices, was also collected.

\section{Questionnaires}

Adapted Facebook Intensity Scale (FIS) An adapted version of the FIS (Ellison et al., 2007) was used to measure the participants' social media usage and attitudes, looking at the extent to which participants were emotionally connected to social media, and the extent to which they were integrated in their social activities. Participants were presented with 8 self-report individual item statements (e.g., "Social media 
is part of my everyday activity") and were asked to respond to each statement using a 5-point Likert-scale, ranging from $1=$ Strongly Disagree to 5=Strongly Agree . The original FIS was developed to measure Facebook usage, however, as the current study was interested in the use of social media in general, all Facebook references within the FIS were replaced by 'social media'. This was the only change made hence the psychometric properties of the original scale were not compromised. The scoring of the adapted version of FIS followed the scoring of the original scale. Therefore, a mean of each item scale was calculated, and the total score achievable ranged from 6 to 30, following the original FIS. The sum of scores indicated participants' social media usage, with higher scores representing greater use of social media.

European Cyber-Bullying Intervention Project Questionnaire (ECIPQ) The ECIPQ (Brighi et al., 2012) was used to assess cyber-bullying victimisation and cyber-aggressive behaviour. Participants were presented with 22 self-report individual item statements, split equally between items that examine cyber-bullying victimisation, and cyber-aggression. They were asked to indicate how often they had experienced or taken part in specific behaviours, in the past 2 or 3 months. For example, "Someone threatened me through texts or online messages" and "I threatened someone through texts or online messages". Participants answered on a 5-point Likert scale, ranging from $0=$ never, $1=$ once or twice, $2=$ once per month, $3=$ once per week, $4=$ more than once per week. The ECIPQ was scored based on the scoring criteria outlined by Del Rey et al., (2015), and total scores were calculated separately for cyber-aggression and cyberbullying victimization.

Rosenberg Self-Esteem Scale (RSES) The RSES was used to assess participants' level of self-esteem (Rosenberg, 1965). This measure is comprised 10 individual self-report items (for example, 'On the whole I am satisfied with myself') rated on a 4-point Likert scale, ranging from $0=$ Strongly agree to $4=$ Strongly disagree. Participants were asked to decide the extent to which they agreed with each statement. The RSES has been extensively used with autistic individuals in past research (e.g., Mazurek, 2014; Hillier et al., 2018; Gordon et al., 2015), has test-retest reliability that ranges from 0.82 to 0.88 , and internal consistency that ranges from 0.77 to 0.88 (Blascovich \& Tomaka, 1993; Rosenberg, 1986; Schmitt \& Allik, 2005). Participant total scores were calculated, and scores can range from 0 to 30 . Higher scores indicate greater levels of self-esteem.

\section{Analysis}

For the first aim, to investigate social media use in autistic adults, descriptive statistics were calculated and summarised. For the second aim, to examine the occurrence of cyber-bullying victimisation and cyber-aggression in autistic adults, descriptive statistics were also calculated and summarised. The Wilcoxon Sign-Ranked test was then used to compare differences between those with a history of cyber-bullying victimisation and cyber-aggression. For the third aim, initially, a series of Spearman's rho correlation coefficients were used to examine the relationships between self-esteem (RSES) and social media (adapted-FIS) use, as well as cyber-bullying victimisation and cyber-aggression data (ECIPQ). Finally, linear regression was used to examine the relationship between either experience of cyber-bullying victimisation or cyber-aggression and age, gender, educational qualifications, time spent online, and the number of friends on social media.

\section{Results}

\section{Social Media Use (Adapted FIS)}

All participants reported to have access to a device that could connect to the internet, and all participants reported using social media (100\%); $27.3 \%$ of participants said that they spent between 1 and $2 \mathrm{~h}$ per day on social media $(n=21)$, while $16.9 \%$ of participants indicated that they spent between 2 and $3 \mathrm{~h}$ per day on social media $(n=13)$; $16.9 \%$ indicated they spent $30-59 \mathrm{~min}$ on social media. Only $5.2 \%$ of participants indicated that they used social media more than $5 \mathrm{~h}$ per day $(n=4)$. The majority of the participants also reported to have more than 200 friends on their social media accounts $(28.6 \%, \mathrm{n}=22)$ with $15.6 \%$ of participants having 10 friends or less $(\mathrm{n}=12)$.

The findings from the adapted FIS (Table 1), which measured social media usage and attitudes, and the extent that social media was part of everyday life suggested that social media was a big part of everyday life and everyday routine, with $85.7 \%$ of participants agreeing it was part of everyday activity, and $77.9 \%$ agreeing that it was part of their daily routine.

\section{Experiences of Cyber-bullying Victimisation and Cyber-aggression (ECIPQ)}

Participants' experiences of cyber-bullying victimisation and cyber-aggression was measured using the ECIPQ. Thirty one percent reported that during the past 2-3 months they had experienced cyber-bullying victimisation $(n=23), 2.7 \%$ reported to have engaged in cyber-aggressive behaviours $(\mathrm{n}=2)$, and $8 \%$ reported to have experienced both cyber-bullying victimisation and acted as cyber-aggressors $(n=6)$. In contrast to this, $58.7 \%$ had no experience of either cyber-bullying victimisation or cyber-aggression. Twenty-four percent 
Table 1 Descriptive statistics for adapted FIS items of the questionnaire

\begin{tabular}{lll}
\hline Adapted FIS items & $\begin{array}{l}\mathrm{M}(\mathrm{SD}) \\
\mathrm{N}=77\end{array}$ & $\begin{array}{l}\text { Agreement- } \\
\text { frequencies } \\
(\%)\end{array}$ \\
\hline Social media is part of my everyday activity & $4.25(1.24)$ & $66(85.7 \%)$ \\
I am proud to tell people I am on social media & $3.01(1.17)$ & $22(28.6 \%)$ \\
Social media has become part of my daily routine & $4.16(1.26)$ & $60(77.9 \%)$ \\
I feel out of touch when I have not logged into social media & $3.32(1.44)$ & $40(52 \%)$ \\
I feel that I am part of a social media community & $3.27(1.29)$ & $37(48.1 \%)$ \\
I would be sorry if social media shut down & $3.40(1.47)$ & $42(54.6 \%)$ \\
Number of friends on social media & $4.14(2.49)$ & - \\
Time spent on social media & $4.00(1.65)$ & - \\
Adapted FIS total & $21.41(5.99)$ & - \\
\hline
\end{tabular}

$(n=19)$ of the participants stated that they were excluded or ignored by others in a social networking site or internet chat room, $23 \%(n=18)$ stated that someone said nasty things about them to others online, and $22 \%(n=17)$ stated that someone said nasty things to them or called them names using online messages. The mean total cyber-victimisation score was 4.88 $(\mathrm{SD}=5.75)$, and the mean total cyber-aggression score was 1.61 ( $\mathrm{SD}=3.33)$. Overall, participants reported experiencing significantly higher cyber-bullying victimisation relative to engaging in cyber-aggression $(z=5.51, p<0.001)$. Table 2 , below, shows a breakdown of the reported frequencies for each of the ECIPQ statements, as well as the total ECIPQ scores for both cyber-bullying victimisation, and cyber-aggression.

\section{Relationship Between Self-Esteem, Social Media Use, Cyber-bullying Victimisation and Cyber-Aggression}

Participants scored an average of 15 out of a possible 30 on the RSES, which measured self-esteem, with higher scores indicating greater levels of self-esteem $(M=15(6.24), \mathrm{n}=78)$. Self-esteem was positively related to the number online friends, $r(77)=0.27, p=0.02$, and seeing oneself as part of an online community, $r(77)=0.29, p=0.01$, as measured by the FIS. There was a negative relationship between self-esteem and cyber-bullying victimisation (ECIPQ), specifically with respect to how often someone else posted personal information about the participants online $\mathrm{r}(75)=-0.25, \mathrm{p}=0.03$, as well as the amount of times participants were excluded or ignored by others on social media, $\mathrm{r}(75)=-0.29, \mathrm{p}=0.01$.

\section{Relationship Between Time Spent on Social Media, Self-Esteem and Experiences of Cyber-Bullying Victimisation and Cyber-Aggression}

\section{Model 1: Cyber-Bullying Victimisation}

A multiple linear regression analysis was carried out in order to model the linear relationship between the time spent on social media, experiences of cyber-bullying victimisation, cyber-aggression, and self-esteem. Model 1 predicted cyber-bullying victimisation, with a significant regression equation $(\mathrm{F}(5,62)=5.796, \mathrm{p}<0.001)$ and a regression coefficient $R=0.564$, suggesting a strong relationship. The adjusted $\mathrm{R}^{2}=0.319$, meaning that $31.9 \%$ of the variance in the cyber-victimisation, was explained by the five predictor variables. See Table 3 for more information about the relationship between time spent on social media and experiences of cyber-bullying victimisation, cyber-aggression, and self-esteem.

Out of the five, there were three statistically significant predictors; time spent on social media $\left(\beta_{\text {time }}=0.430\right.$; $\mathrm{t}=3.998 ; \mathrm{p}<0.001)$, gender $\left(\beta_{\text {gender }}=-0.237 ; \mathrm{t}=-2.153\right.$; $\mathrm{p}=0.03)$ and age $\left(\beta_{\text {age }}=0.220 ; \mathrm{t}=2.010 ; \mathrm{p}=0.04\right)$. The educational qualifications and the number of social media friends were not significant predictors of cyber-victimisation.

\section{Model 2: Cyber-Aggression}

Model 2 predicted cyber-aggression. However, the regression equation was not significant $(\mathrm{F}(5,63)=0.166, \mathrm{p}>0.05)$ 
Table 2 Descriptive statistics for ECIPQ items of the questionnaire

$\begin{array}{llllll}\text { Never [\% (n)] } & \begin{array}{l}\text { Once or } \\ \text { twice }[\%\end{array} & \begin{array}{l}\text { Once per } \\ \text { month }[\%\end{array} & \begin{array}{l}\text { Once per } \\ \text { week }[\%\end{array} & \begin{array}{l}\text { More than once } \\ \text { per week }[\%\end{array} & \text { Mean* (SD) }(\mathrm{n}=75) \\ (\mathrm{n})] & (\mathrm{n})] & \text { (n) }] & (\mathrm{n})]\end{array}$

Cyber-bullying victimisation items

Someone said nasty things to me or called me names using texts or online messages

Someone said nasty things about me to others either online or through text messages

Someone threatened me through texts or online messages

Someone hacked into my account and stole personal information

Someone hacked into my account and pretended to be me

Someone created a fake account, pretending to be me

Someone posted personal information about me online

Someone posted embarrassing videos or pictures $80 \%$ (60) of me online

Someone altered pictures or videos of me that I $\quad 89 \%$ (66) had posted online

I was excluded or ignored by others in a social networking site or internet chat room

Someone spread rumours about me on the internet

\begin{tabular}{|c|c|c|c|c|c|}
\hline $44 \%(33)$ & $33 \%(25)$ & $13 \%(10)$ & $4 \%(3)$ & $5 \%(4)$ & 0.93 \\
\hline $51 \%(38)$ & $25 \%$ & $9 \%(7)$ & $5 \%(4)$ & $9 \%(7)$ & $0.97(1.29)$ \\
\hline $63 \%(47)$ & $28 \%$ & $5 \%(4)$ & $4 \%(3)$ & - & $0.51(0.78)$ \\
\hline $89 \%(67)$ & $9 \%(7)$ & - & - & $1 \%(1)$ & $0.15(0.54)$ \\
\hline $95 \%(71)$ & $4 \%(3)$ & $1 \%(1)$ & - & - & $0.07(0.3)$ \\
\hline $91 \%(68)$ & $7 \%(5)$ & $1 \%(1)$ & $1 \%(1)$ & - & $0.13(0.47)$ \\
\hline $72 \%(54)$ & $20 \%$ & $5 \%(4)$ & $1 \%(1)$ & $1 \%(1)$ & $0.4(0.77)$ \\
\hline $80 \%(60)$ & $16 \%(12)$ & $4 \%(3)$ & - & - & $0.24(0.52)$ \\
\hline $89 \%(66)$ & $11 \%(8)$ & - & - & - & $0.11(0.31)$ \\
\hline $53 \%(40)$ & $21 \%$ & $4 \%(3)$ & $8 \%(6)$ & $13 \%(10)$ & $1.07(1.45)$ \\
\hline \multirow[t]{2}{*}{$71 \%(53)$} & $16 \%(12)$ & $8 \%(6)$ & $3 \%(2)$ & $3 \%(2)$ & $0.51(0.95)$ \\
\hline & & & & & $4.88(5.75)$ \\
\hline $79 \%(59)$ & $15 \%(11)$ & $1 \%(1)$ & $3 \%(2)$ & $3 \%(2)$ & $0.36(0.86)$ \\
\hline $72 \%(54)$ & $17 \%(13)$ & $8 \%(6)$ & $1 \%(1)$ & $1 \%(1)$ & $0.43(0.81)$ \\
\hline $92 \%(69)$ & $7 \%(5)$ & $1 \%(1)$ & - & - & $0.09(0.34)$ \\
\hline $97 \%(73)$ & $3 \%(2)$ & - & - & - & $0.03(0.16)$ \\
\hline $99 \%(74)$ & - & - & $1 \%(1)$ & - & $0.04(0.35)$ \\
\hline $92 \%(69)$ & $7 \%(5)$ & $1 \%(1)$ & - & - & $0.09(0.34)$ \\
\hline $99 \%(74)$ & - & $1 \%(1)$ & - & - & $0.03(0.23)$ \\
\hline $93 \%(70)$ & $5 \%(4)$ & $1 \%(1)$ & - & - & $0.08(0.32)$ \\
\hline $91 \%(68)$ & $8 \%(6)$ & $1 \%(1)$ & - & - & $0.11(0.35)$ \\
\hline $76 \%(57)$ & $21 \%(16)$ & $1 \%(1)$ & - & $1 \%(1)$ & $0.29(0.63)$ \\
\hline \multirow[t]{2}{*}{$95 \%(71)$} & $4 \%(3)$ & $1 \%(1)$ & - & - & $0.07(0.30)$ \\
\hline & & & & & $1.61(3.33)$ \\
\hline
\end{tabular}

Total Cyber-victimisation

Cyber-aggression items

I said nasty things to someone or called them names using texts or online messages

I said nasty things about someone to other people either online or through text messages

I threatened someone through texts or online messages

I hacked into someone's account and stole personal information

I hacked into someone's account and pretended to be them

I created a fake account, pretending to be someone else

I posted personal information about someone online

I posted embarrassing videos or pictures of someone online

I altered pictures or videos of another person that had been posted online

I excluded or ignored someone in a social networking site or internet chat room

I spread rumours about someone on the internet

Total cyber-aggression

$* 0=$ never, $1=$ once or twice, $2=$ once per month, $3=$ once per week, $4=$ more than once per week

and the coefficient was $R=0.114$. Only $1.3 \%$ of the variance in the cyber-aggression was explained by the five predictor variables $\left(R^{2}=0.013\right)$. From the independent variable regression coefficients, none of the predictors were statistically significant. In other words, while the time spent on social media was a significant predictor of cyber-bullying 
Table 3 Model 1: regression for time spent on social media and cyber-bullying victimisation for autistic adults

\begin{tabular}{|c|c|c|c|c|c|}
\hline & \multicolumn{2}{|c|}{$\begin{array}{l}\text { Unstandardized Coef- } \\
\text { ficients }\end{array}$} & \multirow{2}{*}{$\begin{array}{l}\text { Standardized } \\
\text { Coefficients } \\
\text { Beta }\end{array}$} & \multirow[t]{2}{*}{$\mathrm{t}$} & \multirow[t]{2}{*}{ Sig } \\
\hline & $\mathrm{B}$ & $\mathrm{SE}$ & & & \\
\hline \multicolumn{6}{|l|}{ Model 1} \\
\hline Cyber-bullying Victimisation (ECIPQ) & 3.097 & 3.258 & & .951 & .345 \\
\hline Age in years & .133 & .066 & .220 & 2.010 & .049 \\
\hline Male & -2.812 & 1.306 & -.237 & -2.153 & .035 \\
\hline Educational qualifications & .856 & .559 & .170 & 1.532 & .131 \\
\hline Time spent on social media (adapted FIS) & 5.228 & 1.308 & .430 & 3.998 & .000 \\
\hline Social media friends (adapted FIS) & -1.458 & 1.287 & -.125 & -1.133 & .262 \\
\hline
\end{tabular}

Table 4 Model 2: regression for time spent on social media, cyber-bullying victimisation and cyber-aggression for autistic adults

\begin{tabular}{|c|c|c|c|c|c|}
\hline & \multicolumn{2}{|c|}{$\begin{array}{l}\text { Unstandardized coef- } \\
\text { ficients }\end{array}$} & \multirow{2}{*}{$\begin{array}{l}\text { Standardized } \\
\text { coefficients } \\
\text { Beta }\end{array}$} & \multirow[t]{2}{*}{$\mathrm{t}$} & \multirow[t]{2}{*}{ Sig } \\
\hline & B & SE & & & \\
\hline \multicolumn{6}{|l|}{ Model 2} \\
\hline Cyber-aggression (ECIPQ) & 3.339 & 2.317 & & 1.441 & .154 \\
\hline Age in years & -.010 & .047 & -.028 & -.210 & .834 \\
\hline Male & -.674 & .925 & -.096 & -.728 & .469 \\
\hline Educational qualifications & -.101 & .397 & -.034 & -.255 & .800 \\
\hline Time spent on social media (adapted FIS) & -.044 & .926 & -.006 & -.048 & .962 \\
\hline Social media friends (adapted FIS) & .041 & .911 & .006 & .045 & .964 \\
\hline
\end{tabular}

victimisation, it was, however, not a significant predictor for cyber-aggression. Table 4 provides additional information about the relationship between time spent on social media and experiences of cyber-bullying victimisation, cyberaggression, and self-esteem.

\section{Discussion}

Until now, no other study has explored the relationship between cyber-bullying victimisation, cyber-aggression and social media use in autistic adults. The primary aim of the study was to investigate social media use and examine the occurrence of cyber-bullying victimisation and cyberaggression in autistic adults. Social media was found to be a big part of autistic adults' everyday life. In the current study, participants reported social media to be part of their daily routine, feeling 'out of touch' when they had not logged in their social media. This is comparable to previous studies also looking at social media use for autistic adults (Mazurek, 2013). As Facebook is no longer the dominant online platform (Lenhart et al., 2015), the current study looked at social media in general. Autistic adults made use of social media more relative to Ellison et al. (2007) who investigated Facebook use in undergraduate university students. Past research has also shown a positive relationship between autistic traits and compulsive internet use in young adults (Shane-Simpson et al., 2016), which might have also contributed to the observed elevated rates.

Participants also reported higher rates of cyber-bullying victimisation than cyber-aggression in the current study. The prevalence rates of cyber-bullying victimisation reported here $(37 \%)$ is in agreement with prevalence data from the general population (37-70\%; Microsoft, 2012; Cramer, 2018), and with prevalence rates reported for autistic adolescents in Canada (30.4\%; Holfeld et al., 2019). Participants in the current study seem to score higher in cyber-bullying victimisation, when compared to typically developed adolescents and young adults aged 11-23, from 6 different countries (Del Rey et al, 2015). Cyber-aggression rates were low in the current study, and this is also in agreement with data collected from autistic adolescents (Hu et al., 2019; Iglesias et al., 2019; Holfeld et al., 2019).

Whilst exploring experiences of cyber-bullying victimisation and cyber-aggression in autistic adults, as well as social media intensity, the current study also looked further into how these factors may have an association with autistic adults' self-esteem. Previous research has highlighted the negative impact of traditional bullying on individuals' wellbeing by increasing their anxiety, depression and fear (Espelage \& Swearer, 2003). The negative psychological effects of cyber-bullying victimisation on self-esteem (Extremera et al., 2018; Palermiti et al., 2017; Patchin \& Hinduja, 2010) and excessive social media use on self-esteem (Kalpidou 
et al., 2011; Mehdizadeh, 2010), has been well documented in the general population. However, no other study has investigated the relationship between self-esteem, cyberbullying victimisation, cyber-aggression, and social media use in autistic adults. Self-esteem rates were found to be highly correlated with feelings of belonging in an online community and negatively correlated with feelings of being ignored on social network sites and chat rooms. The feeling of belonging in an online community had a positive effect on participants, promoting feelings of pride and usefulness, whereas being ignored on social media elevated feelings of worthlessness and negativity.

The current study also found that high levels of social media use were associated with an increased risk of cyberbullying victimisation amongst autistic adults. Adults who spent more than $2 \mathrm{~h}$ per day on social media, scored higher on cyber-bullying victimisation when compared to those who spent less than $2 \mathrm{~h}$ per day on social media. This is in line with previous research on autistic adolescents with Attention Deficit Hyperactivity Disorder (Kowalski \& Fedina, 2011). Mazurek (2013), in their study also looking at social media use in autistic adults, reported that the majority of their participants used social media to keep in touch with friends and family. Keeping in mind the particular challenges autistic individuals may come across with face-to-face interactions, social media are an attractive alternative mean of communication. Therefore, the associations between cyber-bullying victimisation and social media use highlighted by the current study, are particularly alarming for the autistic population.

\section{Limitations}

Although this is the first study looking at the relationship between cyber-bullying victimisation, cyber-aggression, self-esteem and social media use in autistic adults, there are some limitations that should be noted. The generalisation of the current study's findings should be treated with caution due to the low number of participants involved in the study. Participants were volunteers who might have responded to the call for this study due to their high use of social media and experiences of cyber-bullying victimisation. All measures administered to participants were self-reported measures. Although this could be viewed as a methodological strength in comparison to previous studies (Didden et al., 2009; Kowalski \& Fedina, 2011), it also applied some limitations to the study. The data collected represents participants' own perceptions and memories of cyber-bullying victimisation, cyber-aggression, and social media use. The majority of the participants who responded to the study's call were females, while typically the gender ratio for autism is 3:1 male to female (Loomes et al., 2017). However, no gender differences were highlighted in any of the variables investigated. The participants' cognitive ability and severity of autism was not assessed in the current study, however from the educational level of the majority of the participants, it can be assumed that participants were of average/ high cognitive ability. Additional variables such as type of devices, platforms used, as well as the positive use of social media and risks taken should be included in future research. Finally, it is important to highlight that the data collection of this study took place in 2017 and 2018 and the online experiences of autistic adults may have changed since then, especially with the COVID-19 pandemic. However, the current study has created an invaluable source of comparable data to support further studies looking at how autistic adults' experiences may have changed since the pandemic.

\section{Conclusion}

Even though social media were found to be a big part of autistic adults' everyday life, the results also showed that more adults experienced cyber-bullying victimisation than cyber-aggression. Self-esteem rates were found to be highly correlated with feelings of belonging in an online community and negatively correlated with feelings of being ignored on social network sites and chat rooms, whereas high levels of social media use were associated with an increased risk of cyber-bullying victimisation amongst autistic adults. These results have implications for public awareness, policy makers, and clinicians working in adult health and social services. Future research is required to further investigate social media use and cyber-bullying victimisation in autistic adults, as well as its possible association with self-esteem. There is also a clear need for intervention and increase of awareness around the risks and occurrences of cyber-bullying in this population.

Supplementary Information The online version contains supplementary material available at https://doi.org/10.1007/s10803-021-05361-6.

Author Contributions Conceptualisation, formal analysis, methodology and ethics, writing original draft, reviewing and editing was done by PT. Conceptualisation, data collection, methodology and ethics, project administration was done by $\mathrm{CCH}$. Analysis, validation, reviewing and editing was done by PEL.

Open Access This article is licensed under a Creative Commons Attribution 4.0 International License, which permits use, sharing, adaptation, distribution and reproduction in any medium or format, as long as you give appropriate credit to the original author(s) and the source, provide a link to the Creative Commons licence, and indicate if changes were made. The images or other third party material in this article are included in the article's Creative Commons licence, unless indicated otherwise in a credit line to the material. If material is not included in the article's Creative Commons licence and your intended use is not 
permitted by statutory regulation or exceeds the permitted use, you will need to obtain permission directly from the copyright holder. To view a copy of this licence, visit http://creativecommons.org/licenses/by/4.0/.

\section{References}

Agatston, P. W., Kowalski, R., \& Limber, S. (2007). Students' perspectives on cyber bullying. Journal of Adolescent Health, 41(6), S59-S60. https://doi.org/10.1016/j.jadohealth.2007.09.003

American Psychiatric Association. (2013). Diagnostic and statistical manual of mental disorders (5th ed.). American Psychiatric Publishing.

Blais, J. J., Craig, W. M., Pepler, D., \& Connolly, J. (2008). Adolescents online: The importance of internet activity choices to salient relationships. Journal of Youth and Adolescence, 37(5), 522-536. https://doi.org/10.1007/s10964-007-9262-7

Blascovich, J., \& Tomaka, J. (1993). Measures of self-esteem. In J. P. Robinson, P. R. Shaver, \& L. S. Wrightsman (Eds.), Measures of personality and social psychological attitudes (3rd ed., pp. 115-160). Institute for Social Research.

Blume, A., DeJong, V. D., Kim, Y., \& Sprinkle, B. G. (2001). Evolution of communication with partial common interest. Games and Economic Behavior, 37(1), 79-120. https://doi.org/10.1006/game. 2000.0830

Brighi, A., Guarini, A., Melotti, G., Galli, S., \& Genta, L. M. (2012). Predictors of victimisation across direct bullying, indirect bullying and cyberbullying. Emotional and Behavioural Difficulties, 17(34), 375-388. https://doi.org/10.1080/13632752.2012.704684

Cenat, M. J., Herbert, M., Blais, M., Lavoie, F., Guerrier, M., \& Derivois, D. (2014). Cyberbullying, psychological distress and self-esteem among youth in Quebec Schools. Journal of Affective Disorders, 169, 7-9. https://doi.org/10.1016/j.jad.2014.07.019

Cramer, S. (2018). \#Statusofmind: Social media and young people's mental health and wellbeing. In APHA's 2018 annual meeting \& expo. American Public Health Association.

Del Rey, R., Casas, J. A., Ortega-Ruiz, R., Schultze-Krumbholz, A., Scheithauer, H., Smith, P., Thompson, F., Barkoukis, V., Tsorbatzoudis, H., Brighi, A., Guarini, A., Pyżalski, J., \& Plichta, P. (2015). Structural validation and cross-cultural robustness of the European cyberbullying intervention project questionnaire. Computers in Human Behavior, 50, 141-147. https://doi.org/10.1016/j. chb.2015.03.065

Didden, R., Scholte, R. H., Korzilius, H., De Moor, J. M., Vermeulen, A., O'Reilly, M., Lang, R., \& Lancioni, G. E. (2009). Cyberbullying among students with intellectual and developmental disability in special education settings. Developmental Neurorehabilitation, 12(3), 146-151. https://doi.org/10.1080/17518420902971356

DiMaggio, P. H., Neuman, R. W., \& Robinson, P. J. (2001). Social implications of the internet. Annual Review of Sociology, 27(4), 307-336. https://doi.org/10.1146/annurev.soc.27.1.307

Ellison, B. N., Steinfield, C., \& Lampe, C. (2007). The benefits of Facebook "friends:" Social capital and college students' use of online social network sites. Journal of Computer-Mediated Communication, 12(4), 1143-1168. https://doi.org/10.1111/j.10836101.2007.00367.x

Espelage, D. L., \& Swearer, S. M. (2003). Research on school bullying and victimization: What have we learned and where do we go from here? School Psychology Review, 32(3), 365-383. https:// doi.org/10.1080/02796015.2003.12086206

Extremera, N., Quintana-Orts, C., Mérida-López, S., \& Rey, L. (2018). Cyberbullying victimization, self-esteem and suicidal ideation in adolescence: Does emotional intelligence play a buffering role?
Frontiers in Psychology, 9, 367. https://doi.org/10.3389/fpsyg. 2018.00367

Gordon, K., Murin, M., Baykaner, O., Roughan, L., Livermore-Hardy, V., Skuse, D., \& Mandy, W. (2015). A randomised controlled trial of PEGASUS, a psychoeducational programme for young people with high-functioning autism spectrum disorder. Journal of Child Psychology and Psychiatry, 56(4), 468-476. https://doi.org/10. 1111/jcpp.12304

Gross, F. E., Juvonen, J., \& Gable, L. S. (2002). Internet use and wellbeing in adolescence. Journal of Social Issues, 58(1), 75-90. https://doi.org/10.1111/1540-4560.00249

Hillier, A., Goldstein, J., Murphy, D., Trietsch, R., Keeves, J., Mendes, E., \& Queenan, A. (2018). Supporting university students with autism spectrum disorder. Autism, 22(1), 20-28. https://doi.org/ $10.1177 / 1362361317699584$

Holfeld, B., \& Mishna, F. (2019). Internalizing symptoms and externalizing problems: Risk factors for or consequences of cyber victimization? Journal of Youth and Adolescence, 48(3), 567-580. https://doi.org/10.1007/s10964-018-0974-7

Holfeld, B., Stoesz, B., \& Montgomery, J. (2019). Traditional and Cyber bullying and victimization among youth with autism spectrum disorder: An investigation of the frequency, characteristics, and psychosocial correlates. Journal on Developmental Disabilities, 24(2), 61-76.

Hu, H. F., Liu, T. L., Hsiao, R. C., Ni, H. C., Liang, S. H. Y., Lin, C. F., Chan, H. L., Hsieh, Y. H., Wang, L. J., Lee, M. J., Chou, W. J., \& Yen, C. F. (2019). Cyberbullying victimization and perpetration in adolescents with high-functioning autism spectrum disorder: Correlations with depression, anxiety, and suicidality. Journal of Autism and Developmental Disorders, 49(10), 4170-4180. https:// doi.org/10.1007/s10803-019-04060-7

Iglesias, O. B., Sánchez, L. E. G., \& Rodríguez, M. Á. A. (2019). Do young people with Asperger syndrome or intellectual disability use social media and are they cyberbullied or cyberbullies in the same way as their peers? Psicothema, 31(1), 30-37. https://doi. org/10.7334/psicothema2018.243

Kalpidou, M., Costin, D., \& Morris, J. (2011). The relationship between Facebook and the well-being of undergraduate college students. Cyberpsychology, Behavior and Social Networking, 14(4), 183-189. https://doi.org/10.1089/cyber.2010.0061

Kowalski, M. R., \& Fedina, C. (2011). Cyberbullying in ADHD and asperger syndrome populations. Research in Autism Spectrum Disorders, 5(3), 1201-1208. https://doi.org/10.1016/j.rasd.2011. 01.007

Kowalski, R. M., Giumetti, G. W., Schroeder, A. N., \& Lattanner, M. R. (2014). Bullying in the digital age: A critical review and metaanalysis of cyberbullying research among youth. Psychological Bulletin, 140(4), 1073-1137.

Kowalski, R. M., \& Limber, S. P. (2013). Psychological, physical, and academic correlates of cyberbullying and traditional bullying. Journal of Adolescent Health, 53(1), S13-S20. https://doi.org/ 10.1016/j.jadohealth.2012.09.018

Kraut, R., Kiesler, S., Boneva, B., Cummings, J., Helgeson, V., \& Crawford, A. (2002). Internet Paradox Revisited. Journal of Social Issues, 58(1), 49-74. https://doi.org/10.1111/1540-4560.00248

Ledingham, R., \& Mills, R. (2015). A preliminary study of autism and cybercrime in the context of international law enforcement. Advances in Autism. https://doi.org/10.1108/AIA-05-2015-0003

Lenhart, A., Duggan, M., Perrin, A., Stepler, R., Rainie, H., \& Parker, K. (2015). Teens, social media \& technology overview 2015. British Columbia Teachers' Federation.

Loomes, R., Hull, L., \& Mandy, W. P. L. (2017). What is the male-tofemale ratio in autism spectrum disorder? A systematic review and meta-analysis. Journal of the American Academy of Child \& Adolescent Psychiatry, 56(6), 466-474. https://doi.org/10.1016/j. jaac.2017.03.013 
Mazurek, M. O. (2013). Social media use among adults with autism spectrum disorders. Computers in Human Behavior, 29(4), 1709-1714.

Mazurek, M. O. (2014). Loneliness, friendship, and well-being in adults with autism spectrum disorders. Autism, 18(3), 223-232. https://doi.org/10.1177/1362361312474121

Mazurek, M. O., \& Engelhardt, C. R. (2013). Video game use in boys with autism spectrum disorder, ADHD, or typical development. Pediatrics, 132(2), 260-266. https://doi.org/10.1542/peds. 2012-3956

Mazurek, M. O., Shattuck, P. T., Wagner, M., \& Cooper, B. P. (2012). Prevalence and correlates of screen-based media use among youths with autism spectrum disorders. Journal of Autism and Developmental Disorders, 42(8), 1757-1767. https://doi.org/10. 1007/s10803-011-1413-8

Mehdizadeh, S. (2010). Self-presentation 2.0: Narcissism and selfesteem on Facebook. Cyberpsychology, Behavior and Social Networking, 13(4), 357-364. https://doi.org/10.1089/cyber.2009.0257

Microsoft. (2012). Online bullying among youth 8-17 years oldworldwide. Retrieved from http://download.microsoft.com/ download/E/8/4/E84BEEAB-7B92-4CF8-B5C7-7CC20D92B4 F9/WW\%20Online\%20Bullying\%20Survey\%20-\%20Executive\% 20Summary\%20-\%20India_Final.pdf

O'Keeffe, S. G., \& Clarke-Pearson, K. (2011). The impact of social media on children, adolescents, and families. Pediatrics, 127(4), 800-804. https://doi.org/10.1542/peds.2011-0054

Olweus, D. (1993). Bullying at school: What we know and what we can do. Blackwell Publishing.

Palermiti, A. L., Servidio, R., Bartolo, M. G., \& Costabile, A. (2017). Cyberbullying and self-esteem: An Italian study. Computers in Human Behavior, 69, 136-141. https://doi.org/10.3389/fpsyg. 2018.00367

Patchin, J. W., \& Hinduja, S. (2010). Cyberbullying and self-esteem. Journal of School Health, 80(12), 614-621. https://doi.org/10. 1111/j.1746-1561.2010.00548.x

Payne, K. L., Russell, A., Mills, R., Maras, K., Rai, D., \& Brosnan, M. (2019). Is there a relationship between cyber-dependent crime, autistic-like traits and autism? Journal of Autism and Developmental Disorders, 49(10), 4159-4169. https://doi.org/10.1007/ s10803-019-04119-5

Perren, S., Dooley, J., Shaw, T., \& Cross, D. (2010). Bullying in school and cyberspace: Associations with depressive symptoms in Swiss and Australian adolescents. Child and Adolescent Psychiatry and Mental Health, 4(1), 1-10. https://doi.org/10.1186/ 1753-2000-4-28

Reich, S. M., Subrahmanyam, K., \& Espinoza, G. (2012). Friending, IMing, and hanging out face-to-face: Overlap in adolescents' online and offline social networks. Developmental Psychology, 48(2), 356. https://doi.org/10.1037/a0026980

Rosenberg, M. (1965). Society and the adolescent self-image. Princeton University Press.

Rosenberg, M. (1986). Conceiving the self. Krieger.

Rump, K. M., Giovannelli, J. L., Minshew, N. J., \& Strauss, M. S. (2009). The development of emotion recognition in individuals with autism. Child Development, 80(5), 1434-1447. https://doi. org/10.1111/j.1467-8624.2009.01343.x

Russell, G., Collishaw, S., Golding, J., \& Ford, T. (2015). Changes in diagnosis rates and behavioural traits of autism spectrum disorder over time. Bjpsych Open, 1(2), 110-115. https://doi.org/10.1192/ bjpo.bp. 115.000976

Schmitt, D. P., \& Allik, J. (2005). Simultaneous administration of the Rosenberg Self-Esteem Scale in 53 nations: Exploring the universal and culture-specific features of global self-esteem. Journal of Personality and Social Psychology, 89(4), 623-642. https://doi. org/10.1037/0022-3514.89.4.623

Shane-Simpson, C., Brooks, P. J., Obeid, R., Denton, E. G., \& Gillespie-Lynch, K. (2016). Associations between compulsive internet use and the autism spectrum. Research in Autism Spectrum Disorders, 23, 152-165. https://doi.org/10.1016/j.rasd.2015. 12.005

Shaw, L. H., \& Gant, L. M. (2002). In defense of the internet: The relationship between Internet communication and depression, loneliness, self-esteem, and perceived social support. Cyberpsychology and Behavior. https://doi.org/10.1089/109493102753770552

Smith, M. J., Montagne, B., Perrett, I. D., Gill, M., \& Gallagher, L. (2010). Detecting subtle facial emotion recognition deficits in high-functioning Autism using dynamic stimuli of varying intensites. Neuropsychologia, 48(9), 2777-2781. https://doi.org/ 10.1016/j.neuropsychologia.2010.03.008

Tankovska, H. (2021, Nov 26). Share of respondents who had their own social network profile in the United Kingdom (UK) from 2015 to 2019, by age*. Statista (viewed 23 May 2021). https:// www.statista.com/statistics/271879/social-network-profile-creat ion-in-the-uk-by-age/

Twyman, A. K., Saylor, C. F., Saia, D., Macias, M. M., Taylor, A. L., \& Spratt, E. (2010). Bullying and ostracism experiences in children with special health care needs. Journal of Developmental and Behavioral Pediatrics, 31(1), 1-8. https://doi.org/10.1097/DBP. 0b013e3181c828c8

Valkenburg, M. P., \& Peter, J. (2007). Online Communication and adolescent well-being: Testing the stimulation versus the displacement hypothesis. Journal of Computer-Mediated Communication, 12(4), 1169-1182. https://doi.org/10.1111/j.1083-6101. 2007.00368.x

Valkenburg, M. P., Schouten, P. A., \& Peter, J. (2005). Adolescents' identity experiments on the internet. New Media \& Society, 7(3), 383-402. https://doi.org/10.1177/1461444805052282

Wright, M. F. (2017). Cyber victimization and depression among adolescents with intellectual disabilities and developmental disorders: The moderation of perceived social support. Journal of Mental Health Research in Intellectual Disabilities, 10(2), 126-143. https://doi.org/10.1080/19315864.2016.1271486

Publisher's Note Springer Nature remains neutral with regard to jurisdictional claims in published maps and institutional affiliations. 